\title{
PROBLEMS OF CREATIVE ISSUES AND DEVELOPMENT OF THE PROFESSIONAL COMPETENCES OF THE DIRECTOR OF THE THEATER ART
}

\section{Donchenko N. P.}

\section{INTRODUCTION}

Today, the new socio-cultural situation in the country convinces theorists and practitioners of theatrical art in need to understand the movement of the laws of organic creativity in time, in the real historical development of art.

The overwhelming majority of directors, actors and other workers of the performing arts, perfecting their professional skills, profoundly penetrating the essence of life processes, mastering and using the creative heritage of their great predecessors, boldly seeking their own, fresh and original solutions to current creative issues, contemporary creative problems, assists the people of Ukraine in building a new state.

Modern psychological and pedagogical problems and methods of professional education of theater directors and actors require a multifaceted approach. From the wide range of concepts, that the director - the creator of the art, the actor - the phenomenon of culture, it is necessary to be able to answer very urgent questions: what is the directing, what is its place and role in human culture, what are the creative abilities of the director, who make masters of theater art from the ordinary person? Here is a direct outlet to practical inquiries of stage pedagogy - such a difficult and important problem today.

Improvement of theatrical pedagogy is possible only with the dialectical interaction and interpenetration of three main factors: creative search for practitioners, constant appeal to the pedagogical heritage of the dramatic figures of the past, and active use of achievements of modern science in the theatrical and educational process.

\section{Problems of creative issues of contemporary theatrical art}

Objective factors in the development of theater are the contemporary processes in the theatrical world, the complexity of the tasks that are set before the arts in general, the level of education of the viewer. Today, art is not only obliged to satisfy the many diverse spiritual needs of the people but to nurture it aesthetically and morally.

The second critical moment in the development of the performing arts is the requirements of the theater production itself. This includes the complexity 
of the leadership tasks of forming a modern creative team: the dramatic rejuvenation of all theater art, the development of stage technique, and technology of directing and acting.

Also, most importantly - the breadth of use of the director's profession. Directing has penetrated all spheres of spiritual life. Theatricalization (also directing) has become a necessary component of our social existence. It is hard to imagine without theater or theatrical presentation, nominations, shows, various mass events, sports shows, television. Almost the entire population of the country became a theatrical audience. This very much hinders the formation of requirements for the future director of the theater.

The magnitude of the use of directing creates a false sense of accessibility, ease of profession. Acting does not work, I will go to directors - it became the most common phenomenon in theatrical circles. A misunderstanding of the director's leading role often leads to a misunderstanding of the "prestige" of the director's position.

The theater has accumulated a vast literary legacy regarding the practice of directing creativity, studying which a young director should understand the practical need for theory, and nurture the desire for education. On this occasion, Stanislavsky noted: "It is not difficult to understand the meaning of the words of these great traditions, but unfortunately, it is challenging to feel the artistic essence of their spiritual essence. Meanwhile, it is this side of the past that is important to us because it can bring artists practical benefits" ${ }^{1}$. CBut traditions cannot be created; they can only help the creator, direct creative work, and prevent mistakes. The young director must penetrate the treasure trove of the spiritual essence of tradition. It is not a simple acquaintance, and the analysis of the traditions of the past in terms of their inner spirit will benefit the practical activity of the director. "Beautiful magnifies the life of the human spirit on and off the stage, in other words, the feelings and thoughts of artists and viewers," said Konstantin Stanislavsky ${ }^{2}$.

However, not all theatrical figures correctly understand the use of creative heritage in their work. In search of something new, they turn their eyes to the phenomena of the dramatic life of the first half of the twentieth century. For example, some young filmmakers are using the manner and directorial explication of Les Kurbas in their productions; they, so to speak, "inherit" the legacy of a well-known director. But, unfortunately, in this way, they only copy and repeat the great master of the scene, using only the outward signs of his performances. Creativity is entirely absent here. However, Les Kurbas's rich experience is highly valued, especially in the field of development of acting

\footnotetext{
${ }^{1}$ Stanislavsky K.S. (1954-1961). Collection of Endeavors: In 8 vol. 5. Moscow: Art, p. 481.

${ }^{2}$ Ibid. Art, p. 199.
} 
techniques. "The time for directing experiments is over. The only thing that will always be in the theater is a live actor, attractive person and his talent ... When there is only a director in the performance, it is not long-lasting" ${ }^{3}$.

Scientific achievements, practical experience of directors and actors of the past and contemporary theater arts should be studied, professionally analyzed, and not mistakenly striving to be original at any cost, to impress the viewer with some unusual stage effects. Because the higher the educational level of a specialist, the higher he is in the step in his activity.

Collective creativity is a challenging thing. An actor must possess high moral qualities so as not to be tempted to feel better, among others, when he hears the applause of the audience. Of course, the success of the master should be applauded by the viewer, but he needs to understand the action of the audience as a thank you for his relevant creative work, as getting paid for productive work.

Much of the acting and directing work is based on selfishness and vanity, on the pursuit of public success, and this is not a drawback, but the need to recognize a successful creative act here and now. The theatrical actor is always waiting for applause; he wants the recognition of the viewer, his gratitude. Unsuccessful creativity does not satisfy him because the rehearsal process alone will not please him. The actor and director are sensitive to the praise, keenly react to the criticism, and do not take an utterly indifferent attitude towards them.

Often, in art, there are times when envy or jealousy arises from an actor or director from the success of a colleague who works with them in one creative team. The collective, collegial essence of theatrical art involves the individualization of the personal interests of the artist in a dialectical relation with the benefits of other artists and colleagues. But since individual human and creative interests tend to coincide, it is not uncommon for creative envy to be mixed with personal envy.

The young director has this envy even more dangerous. To assert himself, to win in creative competition with another director, he can get only successful production of the performance. It is hard to see that the director's desire to be above his colleague can generate in the work of the play. It is not about creativity, ethics, not author and actor. Envy does not allow learning from others; it gives birth to "quality." "You love art in yourself, not yourself in art... There are no small roles, but there are small actors. The intrigues, the envious, mercilessly banished from the theater" ${ }^{4}$. This winged phrase of Konstantin Sergeyevich does not cease to be repeated in every theater today. But,

\footnotetext{
${ }^{3}$ Kurbas L. (1988). Berezil. Kyiv: Dnipro, p. 43.

${ }^{4}$ Stanislavsky, K.S. (1947). Ethics. Moscow: Art, p. 16.
} 
unfortunately, it did not become the law of theatrical activity. It still requires enormous hard work by the artistic directors of the theatrical institutions, able to follow the moral and ethical principles of the Stanislavsky system by their example.

The desire to be a good director has nothing to do with others being bad. The more successful directors, the richer the theater, the higher the capacity of each director, because this profession consists of collective experience. Whether they want it or not, directors learn from each other.

"The biography of a true artist is a biography of a person who is constantly endured by dissatisfaction with himself. A true artist becomes not only because of the abilities given to him by nature but also because of the great work of grinding his natural abilities. The artist becomes a true master by constantly learning, constantly observing, and reflecting and consolidating what lies in the sphere of the worldview. <..> Do not worry about any doubts always satisfied amateur. The master is always rigorous to himself; the master is not peculiar to pleasure" 5 .

The young gift is characterized by a heightened sense of prestige of his profession and his place in it. He seems to think that his work is the most important that his work is the most outstanding. It is wrong if the young director understands the prestige of the profession as exceptional and elite and recognizes his creative work as the best. "The creative understanding of the theater director with the theater troupe and the director with the composition of the play is an important issue in the existence of each theater. There are so many wonderful words, articles, and books written about it, so many indisputable truths established and so many wonderful recipes created that one can only wonder where bad actors, boring directors, and unsuccessful performances come from ...”6.

With the advent of cinema, the theater panicked, warmed by illiterate slogans that cinema is the essential form of art. Thus, cinema took its place in the culture, first of all, as a new invention of human progress, which gradually gained aesthetic momentum with the advent of film directors, operators specialists in this field.

But, all kinds of art created by humanity for its entire existence must coexist well and occupy a niche in the aesthetic life of society.

Theater should not be involved in film, television, or other technical spectacles that will undoubtedly emerge in the third millennium. The theater does not need in its creative work the accumulation of artistic and expressive means of cinema, directing techniques of films - rapid change of events,

${ }^{5}$ Meyerhold V.E. (1968). Articles, letters, speeches, conversations: In 2 vols. Vol. 2. Moscow: Art, p. 348.

${ }^{6}$ Akimov N.P. (1978).Theatrical Heritage vol. 2. Leningrad: Art, p. 194. 
internal monologues, voice texts, and more. It has its form - a play with its various genres and, following them, directing techniques and accents.

The primary weapon of the theater that can compete with cinema is the action of an ensemble that takes place on the stage before the audience, not fixed on film. The theatrical performance of the play every time comes into invisible contact with the viewer, and the actor can feel the reaction of the audience, which is invaluable in the creative activity of the master. During the performance, the actor and the viewer coexist with the characters of the play, with them going through a number of events. "You're in the theater! You're the part of it. And theater, remember, it's a mat and two artists. That's all. And sometimes even a rug isn't there. It's just two artists. And we say the Internet, the virtual space..." viewer the veracity of the artistic images. The viewer must say, "I believe."

To penetrate the spiritual depths of the role, the artist, the viewer, can only be through nature itself. The keys to the treasures of the creative subconscious are provided by the very organic life of the human artist. She knows the secrets of her inspiration and the way to it. Only nature can work a miracle, without which it is impossible to revive the dead letters of the role text.

Through the artist's conscious psycho-technics, the subconscious creativity of her organic nature is such and only such a way for the master to fulfill the role. Each director has his or her means of working with the actor, and it is impossible to approve once and for all the established rules for this subject. But the primary stages and psychophysiological techniques of this work, taken from our very nature, still need to be followed in detail. They need to know, check, test themselves, and the director and actor. But also, you need to have all sorts of options that can be used following the conditions of creativity and individual characteristics of the performers.

"What does it mean for a director to be modern? <...> The main thing is to understand the concept of modernity in art. In my opinion, it is a great public understanding of what we are doing, on the one hand, and high mastery of our skills, and ability to penetrate the depths of the human heart - on the other" ${ }^{8}$, G.O. Tovstonogov spoke at a meeting with a new generation of directors of Ukraine.

Nemirovich-Danchenko owns a beautiful phrase: "An artist is like a cyclist, he cannot stop - he will fall." This catchphrase once again reminds us of the law of life - the continuous movement of all that exists, and this law is central to art: not to stop, develop, move forward with society. For action is a life in which the theater is its most crucial servant, fulfilling all its desires.

${ }^{7}$ Heifetz L. (2001). Calling. Moscow: GITIS, p. 14.

${ }^{8}$ Tovstonogov G. (1963). To reproduce the truth of life. From the book: Stanislavsky and Modernity. Kiev: Art, p. 140. 
It must be remembered that our country as an independent state has only existed for the third decade. And the movement to create an independent nation among other countries is extremely rapid, as required by the third millennium.

Life is moving very fast, and the director must have time to study it. What has become the object of his attention today will not be tomorrow because everything will change. Including especially the human relations change gradually, the human psyche is the primary material for artistic creativity. Today, here, now must be the law of stage existence.

What does our modern life look like? What does his contemporary admire? What does the viewer want to hear and see on stage?

Innovative directors develop their fantasies to such an infinity that the viewer is not able to understand in new trendy techniques that he is watching and where he has been invited. It is not at all about aesthetic pleasure from what you have seen.

It is appropriate to mention the play "One Day of Ivan Denisovich" based on the story of O.I. Solzhenitsyn in the production of director A. Zholdak on the stage of Taras Shevchenko Kharkiv State Academic Theater, which premiered in the spring of 2003. It was an experiment, but it is far from theatrical, and the shock that audiences have received (and this is no exaggeration) will remain in their memory. "For full contact, for total truth", according to Stanislavsky, Zholdak had a great desire to place actors on a cage with dogs for a month, so that they could reincarnate, feel real torment. However, culture officials have not yet given permission ${ }^{9}$. However, what has happened on the stage of such a well-known and revered theater does not need to be mentioned, tossed paper, and discussed in the press and theatrical circles, not to suggest re-watching. "Local critics write about Zholdak ... Like all the disadvantages, he challenges the culture of the Ukrainian province. And the people bring down the shaft of it, even the one that bypassed the theaters before the tenth because the fresh spirit hears! As a witness, I will say: a performance smelled, but hardly with Solzhenitsyn...”10.

Such a "naturalistic" performance can hardly be called a product and standard of the present. Nowadays, with the change of political system in the country, many people change their worldview, there is a collapse of ideals, concepts, new qualities of morality are formed. Therefore, art should not carry out false experiments, mix the palette of bright colors of creativity with the filth of everyday life, which, unfortunately, is lacking in the young state.

Consideration of the process of becoming a director-artist is not possible without taking into account the whole variety of socio-cultural characteristics.

\footnotetext{
${ }^{9}$ Musafirova O. (2003). One Day of Naked Ivan Denisovich, Komsomolskaya Pravda,
} April. P. 7.

${ }^{10}$ Ibid. P. 7. 
Social needs, ideological values, socially-oriented norms, concrete, and historical conditions for the existence of art are the components that shape both the modes of artistic activity and the standards of perception and personal settings of the artist. It is necessary to study the personality of the director comprehensively, to find his essence on the border of social and psychological characteristics, to comprehend it as a phenomenon of human culture.

\section{Formation of creative abilities, skills, and techniques of the future director}

The development of the creative abilities of the future specialist of theatrical art becomes one of the priority tasks of special education. The progress and future of Ukraine in the 21st century ultimately depends on how creative the potential of each specialist in their professional field will be realized.

The theatrical community is concerned that there are many unresolved problems and significant shortcomings in work with the directing staff, their preparation, placement, and education.

Without pretending to analyze all the problems associated with directing, I would like to focus on the main thing - becoming a young director, developing his skills as a specialist in the theater.

Insufficient efficiency in training directors, excessive activity in solving quantitative rather than qualitative tasks in the production of young professionals raises doubts: should we study directing at all? And is it possible to master this art at all?

Existing in the theatrical environment, the idea that a director needs to be born allows some skeptics to reject the principles of theatrical training and reduce directing training to a single practice, the development of craft techniques.

In the history of the theater, there are many examples of the appearance of directors outside the educational system. For example, most of the leading Ukrainian and foreign masters of the first half of the twentieth century had no higher theatrical education. But this does not mean that they did not study directing, were not educated as artists, and that only practical crafts are their only university.

Turning to the creative practice of the artists of the 20-40s of the last century, we can see that all of them are obliged to direct their birth to their teachers because they were brought up under their influence, had great models, and studied on these models.

The misconception of the director's primary role often leads to a misunderstanding of the "prestige" of the director's position. Some supporters claim the versatility of directing as a profession. From our point of view, even the most talented director cannot be at the same time a specialist in drama, music, television, mass action, and variety show. Of course, exceptions are possible, but they only confirm the general rule. 
One of the main conditions of conformity to the directing profession is the presence of pedagogical instinct, that is, the combination of abilities to pedagogy with love for life, for man. Not only because directing is impossible without educational techniques and skills, but also because very often pedagogical abilities help the director to achieve aesthetic results.

Pedagogy - as a type of activity - is impossible without love for the person, without the desire to help her. Without these factors, artistic creativity is also unimaginable. A real master and a true artist are the personalities who stand side by side; the address of their activity is a person, their spiritual world. A pedagogical gift - an excellent quality of the human heart - is necessary for the directorial business.

Through man and man - the appointment of the director and his purpose. Because of a sense of thought, of consciousness, this is a feature of our national theatrical art. The nature of the director's thinking is unusual. If it remains in the sphere of the mental process alone, it will always be limited, because the separation of feeling and thought will thereby violate the truth of life. The holistic worldview of the artist consists of consciousness and subconscious, and it is impossible to tear one from the other and absolutize one of them. Therefore, not only logical but also imaginative thinking is essential for the director.

The Ukrainian Higher Theater School has a robust specialized base that has accumulated a variety of pedagogical experience of theater masters of different generations. Advances in current pedagogy, such as teaching programming and game theory, have long been an integral part of the teaching process in directing. Exercise, etude, episode, performance are multifaceted targeted software "installations." Each task is solved by the student under the supervision of the teacher, and the level of its production is evaluated not only by the tutor but also by the staff of the department. The theory of games is also continuously used, since practical training in directing is required in the conditions of play, that is, the execution of creative tasks in artificially created, close to the theatrical process situations. Everything in the director's training is done as if in a real theater; the student is deprived of the need to achieve an instant result. So the process of directing and acting is more interested in him than the result itself.

One of the essential principles of a director's education is the organic combination between theoretical and practical learning of disciplines and practice in cultural and theatrical institutions. Particular attention should be paid to the development of students' creative initiative, the ability to solve artistic problems independently. The theater-directing school is built on the direct creative union of the teacher and the student. And this is not a simplified way of teaching, but a reflection of the specifics of the theater arts. 
Therefore, in the conditions of the theatrical higher education institution, the personality of the teacher has a decisive and no equal impact on the formation of young creators. Graduates of higher education are rightly proud that they have learned from such a master, and the more he is, the more impressive they are. The staffing of the pedagogical departments of directing theatrical, educational establishments of the most famous and talented figures of directing creates the main prerequisite for the qualitative training of directing personnel.

However, the individualized and purely practical training in directing is mostly spontaneous. It is most difficult to achieve harmony, logic, consistency, and completeness of education. Implementation of the program conceived by the teacher for a semester or a year is complicated, as a rule, by the lack of precise planning of each lesson - general or individual. The teacher is often densely guided by the laws of the artistic and production process, and this justifies itself when approaching training to the conditions of the theatrical output. However, in higher education, there is and is developing a methodology peculiar to teaching - that in pedagogy has acquired the definition of educational didactics.

Didactics in secondary school have long become the basis of their own education methods of teaching subjects. In contrast, private higher education methods are composed mainly based on the personal experience of their authors, and their qualities are very diverse. Some higher education professionals question the very possibility of a higher education didactic, seeing it as a prescription and formality in teaching subjects. Meanwhile, in the educational process of higher education, with all the variety of disciplines, forms and methods of educational work, there are general pedagogical (didactic) moments, the knowledge of which can significantly help in the construction of the entire educational process.

Based on the principle of scientific, in the light of the other tenets of didactics of higher education, a scientific manual on the theory of directing should be created. From our point of view, it cannot be a reflection of anyone, even if a bright and fruitful direction. The manual should be based on the generally accepted laws of theatrical creativity, contain an analysis of various ways of theatrical practice from the standpoint of methodological principles of art and scientific theory of directing. Criteria for directing theory and practice must be sound and time-tested.

Of course, the most up-to-date tutorial will not replace the teacher or the learning process. The book contains information, but the student acquires knowledge using everything that gives theoretical and practical lessons, independent work, educational, and industrial practice. The tutorial is a training guide addressed primarily to students. It is challenging to write such a directing guide because its author will be captivated by numerous practical wishes and 
instructions because to know in art means to be able. Therefore, it is possible to create a training manual only as a systematic presentation of knowledge of what directing is, not how to learn to direct. For example, general and basic information about the director's creativity, the essence of the profession, its fundamental public purpose should be outlined in the manual, and ways of mastering the profession of the director - in the program of teacher's activity.

Difficulties in creating a textbook on directing theory are also since directing theory itself is not yet integrated into holistic science, is not systematic, not classified, its research tool is not yet perfected. However, the creation of a textbook on directing will help to build the theory of directing into a strictly scientific field of art criticism.

Thus, the implementation of the principle of exact science in directing pedagogy will be successful and exciting if the theater educational institution performs: a) improvement of the fundamental, theoretical training of the student-director; b) the creation of a particular training manual on the theory and history of directing.

Pedagogy as science has long proven that the most effective way of learning and education - in the development of the creative initiative of the student, in the formation of his ability to self-education. The student can consolidate the acquired knowledge only in one way - independent creative search, practical solution of problem situations, creative tasks. That is why the primary method of transferring knowledge in higher education is practical training in directing, which should be understood as a time-consuming pedagogical technique aimed at developing student initiative.

In teaching directing the didactic principle of linking theory with practice, practical experience with science is not merely necessary. He is the sole and paramount condition of comprehension of the directing profession, as well as one of the essential qualities of a director whose essence of professional activity is the ability to turn scientific knowledge into an efficient production of a performance.

In his book Poetry of Pedagogy, M.I. Knebel writes: “...I regret directors who are not engaged in pedagogy. They do not know what a strange feeling it is to watch flowers opening, as your eyes are born with what you just anticipated, predicted. You helped, your patience and your love did the work. You helped to give birth to something new alive. But I regret those educators who have closed their actions only with pedagogy... No, it is necessary, as long as there is still enough strength, to engage in both pedagogy and directing. It is necessary to stage performances in the theater and educate young people in the institute, to take and give them here and here, to study both from old and in youth"11.

\footnotetext{
${ }^{11}$ Knebel M.O. (1976). Poetry of pedagogy. Moscow: Enlightenment, p. 519.
} 
Therefore, an essential quality of training is the constant and daily work on themselves, to consolidate in the practical stage activity of the acquired knowledge and skills.

The subtleties of constructing the educational process in higher education are based on the fact that following the principles of educational didactics requires the teacher (especially young) constant self-control and continuous improvement. Successful combination of abstract thinking with clarity of teaching can only be a teacher who has the art of instant analysis made by student work, that is, a teacher who has a professional skill.

It should not be reduced to popularization, simplicity in explaining the essence of the directing profession, and the principle of accessibility of knowledge. The success of teaching depends mostly on how the unique science and the form of its education are combined with the individual characteristics of the student. The accessibility of teaching also includes enthusiasm for the learning process; the achievement of artistic result activates the student.

The art of theater educator, first of all, is the ability to find such a task or to pose such a problem that would allow the student to work most productively and receive, from this, the maximum benefit.

The principle of consistency and consistency in teaching directing should be reflected in the activities of the teacher and the student. First of all, systematicity and consistency must be strictly adhered to in the student's mastering of the elements of acting and directing.

Two didactic principles - the principle of consciousness, activity, and independence of students directly in educational work and the principle of connection of individual search for knowledge in educational work with the staff are crucial in shaping the professional skills of a young director. In these principles, the essence of the directing profession is more precise and more profound.

So, let's note the main ways of forming a director:

- improvement of the method of selection of candidates for directors. Development of scientifically sound criteria for determining the directorial skills and, on this basis, new rules for admission to directing specialization;

- increase of fundamental, theoretical training of student-director. Strengthening of the particular cycle of disciplines at the expense of art theory, creation of the scientific approach of directing and manuals on specialty;

- a thorough study and thoughtful system of mastering the theoretical and creative heritage of prominent Ukrainian directors;

- intensification of the educational process based on the sequence of learning in complete accordance with the principles of educational didactics, qualitative use of available opportunities, activation of the creative initiative of the student-director. A deep and close connection between theoretical and 
practical knowledge. Creation of conditions for revealing the student's professional readiness, education in him/her independence and conscious attitude to mastering the profession;

- fixing the relationship of the educational institution with the cultural and theatrical institutions of the country;

- formation of an ethical platform of a young director, education of pedagogical abilities as necessary qualities of the director - the leader of the creative process, and then the team.

The student should master the profession of the director only: no books, no advice, no instructions, no instructions, no request will not be useful if he is unable to work, because in the presentation he embodies his thoughts, his understanding of the world.

All the pedagogical efforts of the directing teachers, all the knowledge gained in the audience, are checked by educational and production practice.

Again, the decisive role in the implementation of the entire curriculum belongs to the teacher in the specialty, the creative atmosphere of the classes and the personality of the teacher will always be the central moral stimuli of educational work with the student-director. Famous teacher and director A. Goncharov writes in this regard: "...I started teaching at the State Institute of Theater Arts 30 years ago. I've been directing for a while longer. But if I had ever been faced with the need to give up something - directing or theater pedagogy I would not know what to decide. Because I don't understand how some directing masters do without pedagogy; think they are stealing themselves. Not to mention the sense of responsibility for the future of our theater" ${ }^{\text {, }}$.

The whole principle of study at a higher education institution of culture and the arts is aimed at theoretically and practically preparing the student for a meeting with a professional art institution. Still, no perfectly organized learning process can replace the atmosphere of a professional institution. No matter how hard we try to get our studies closer to the theater, it won't work - these are different things. And it is not necessary to turn high school into production and to burden production with "school" problems. Higher education institution gives and fulfills the attitude to the chosen profession, nurtures the desire for creativity. Indepth, the wisdom and sophistication of the director's work are learned by a specialist in the theater. The student has the right to make mistakes only at the school desk. In production, his mistakes become the mistakes of an art institution.

Theatrical educators are often rebuked for creating a "perfect" view of the theater for students, but a "real" one would be required because the "deep abyss" lies between these ideas and the graduate's encounter with the theater

${ }^{12}$ Goncharov A.A. (1978). Higher instance. In the book: Your debut. Moscow: Young Guard, p. 49. 
frightens him. And teachers do not create any imagination. They bring up the right attitude to the art of theater that a true creator needs in whatever conditions he or she would work. But in the theater, you do not need to study for the director; in the theater, you need to become a director - that is, you should be responsible for yourself and the theater team.

Much in improving the training of directors depends on how well individual and collective training, individual and collective creativity are combined in a higher education institution. It is in high school that the high principles of theatrical ethics are laid, which provide the director with the ability to unite the creative team in the common cause. And if we consider that it is impossible to study a common business without a collective in the directing profession, it is also clear that the future specialist will not mastered the skills of mastery. The aspiring director must understand the power of creative association around the creation of a work of art. As theater is a collective thing, so does the price of creative friendship and human unity. This gives the future director, in our view, a great deal, because it helps him to penetrate the laboratory of their creativity, to understand the nature and specifics of talent. In general, the value of creative friendship in a theatrical institution of higher education for the education of future professionals in the theater arts is very significant. Dramatic science and pedagogy are still quite poorly developing the problems of collective forms of vocational training in creative higher education, the influence of creative friendship, unanimity on the formation of the personality of the young creator. This is especially true for the training of future directors - collectivists by the nature of their work. The theater teacher, and with him the student-director, should be guided in the construction of the educational process on the collective of theatrical creativity and the complexity of the director's profession.

The director's role is especially multifaceted; he combines a philosopher, playwright, psychologist, historian, artist, musician, literary critic, teacher, theoretician, critic, administrator, etc. Therefore, a great invaluable role in the education of the director-collectivist can play educational material that brings together students of the director's course, and the attitude of teachers to the collective forms of creativity.

\section{CONCLUSIONS}

Leadership in the arts is an extremely subtle and sophisticated thing. The director in the creative process is a sole leader, educator, organizer. Organization of creativity - is the definition of a common problem of the collective, the union of all workers in the artistic and public direction of the theater. Taking care of the collective, of each member of the collective is the first and indispensable condition for creative and organizational leadership in 
the theater. Theater history, current practice shows that actors most often and effortlessly follow the Master. If the director has a clear pedagogical instinct, enthusiasm, and interest in the circle of people around him, he can become an artistic leader. Of course, provided he has a specific and clear artistic program.

The pedagogical orientation of the directing profession is often manifested in need to bring to the general highly professional denominator the manifestations of different principles of acting. The central negative aspect of our higher theatrical school is the difference in the level of teaching staff, in the methodology of teaching, the weak cultivation of the love of the actor in the technology of his profession. In turn, in the conditions of rigid theatrical production, the young actor sometimes has to face such a "diversity" of directing schools that no system of education and training is no longer in question.

\section{SUMMARY}

In-theater pedagogy is a vital necessity for contemporary theater. Not luxury but a necessity. Continuous professional development of artists is required. Therefore, it is necessary to rebuild the internal order of the theater company and find time to educate actors in the wisdom of their profession. Along with the most crucial area of teaching, acting is the need to engage in ethical work in theater. The ethics and discipline of the actors should be exemplary, and the ethical education of the director should be of a higher order because it rests with the great responsibility of the creative leader-teacher.

Life does not stop, and so does art. In the third millennium, new talents will emerge, new arts will develop. The possibilities of the theater will be even more endless. Almost every piece of prose by the forces of theater today. Of course, the theater will feel the influence of other, new kinds of art and mass media, but it will be worthy and noble to defend its form, its style, the purity of genres polished over the centuries.

\section{REFERENCES} [in Russian].

1. Akimov N.P. (1978).Theatrical Heritage vol. 2. Leningrad: Art

2. Goncharov A.A. (1978). Higher instance. In the book: Your debut. Moscow: Young Guard [in Russian].

3. Knebel M.O. (1976). Poetry of pedagogy. Moscow: Enlightenment. [in Russian].

4. Kurbas L. (1988). Berezil. Kyiv: Dnipro [in Ukrainian].

5. Meyerhold V.E. (1968). Articles, letters, speeches, conversations: In 2 vols. Vol. 2. Moscow: Art [in Russian].

6. Musafirova O. (2003). One Day of Naked Ivan Denisovich, Komsomolskaya Pravda, April P. 3. [in Russian]. 
7. Stanislavsky, K.S. (1947). Ethics. Moscow: Art [in Russian].

8. Stanislavsky K.S. (1961). Collection of Endeavors: In 8 vol. 5. Moscow: Art [in Russian].

9. Tovstonogov G. (1963). To reproduce the truth of life. From the book: Stanislavsky and Modernity. Kiev: Art [in Ukrainian].

10. Heifetz L. (2001). Calling. Moscow: GITIS [in Russian].

Information about the author: Donchenko N. P., orcid.org-0000-0003-1484-6800 Honored Artist Ukraine, Professor, Professor of Research Institute Kyiv National University of Culture and Arts 36, Konovalets str., 01601, Kyiv, Ukraine 